OPEN ACCESS

Edited by:

Chirstian Wöber,

Medical University of Vienna, Austria

Reviewed by:

Gianluca Serafini,

San Martino Hospital (IRCCS), Italy

Paolo Martelletti,

Sapienza University of Rome, Italy

${ }^{*}$ Correspondence:

Monira Alwhaibi

malwhaibi@ksu.edu.sa

Specialty section:

This article was submitted to

Headache and Neurogenic Pain,

a section of the journal

Frontiers in Neurology

Received: 26 January 2021 Accepted: 13 April 2021

Published: 21 May 2021

Citation:

Alwhaibi M, Meraya AM and AlRuthia Y (2021) Healthcare

Expenditures Associated With

Comorbid Anxiety and Depression Among Adults With Migraine.

Front. Neurol. 12:658697.

doi: 10.3389/fneur.2021.658697

\section{Healthcare Expenditures Associated With Comorbid Anxiety and Depression Among Adults With Migraine}

\author{
Monira Alwhaibi ${ }^{1 *}$, Abdulkarim M. Meraya ${ }^{2,3}$ and Yazed AlRuthia ${ }^{1,4}$ \\ ${ }^{1}$ Department of Clinical Pharmacy, College of Pharmacy, King Saud University, Riyadh, Saudi Arabia, ${ }^{2}$ Department of Clinical \\ Pharmacy, College of Pharmacy, Jazan University, Jizan, Saudi Arabia, ${ }^{3}$ Pharmacy Practice Research Unit, College of \\ Pharmacy, Jazan University, Jizan, Saudi Arabia, ${ }^{4}$ Pharmacoeconomics Research Unit, College of Pharmacy, King Saud \\ University, Riyadh, Saudi Arabia
}

Introduction: Depression and anxiety are common among patients with migraine and usually associated with a humanistic and financial burden. This study aims to examine the direct healthcare expenditures among adults with migraine alone or with comorbid anxiety and/or depression.

Methods: This was a retrospective cross-sectional study using 2012, 2014, and 2016 Medical Expenditure Panel Survey data. Adult patients aged $\geq 22$ years with migraine headache were included in the study. The direct healthcare expenditures of four migraine groups (migraine alone, migraine and anxiety, migraine and depression, and migraine and both conditions) were compared.

Results: There were 1,556 patients who met the inclusion criteria and eventually enrolled in the study. Approximately $42 \%$ of the study sample had migraine with comorbid depression and/or anxiety (16.1\% have depression, $12.3 \%$ have anxiety disorder, and $13.9 \%$ have both). The mean total healthcare expenditures of adults with migraine alone $(\$ 6,461)$ were significantly lower than those with comorbid depression and anxiety $(\$ 11,102)$, comorbid anxiety $(\$ 10,817)$, and comorbid depression $(\$ 14,577)$. Migraine with comorbid anxiety and depression was significantly associated with incremental costs of \$1,027 in outpatient and \$662 emergency room healthcare expenditures and prescription drug compared to the migraine alone group.

Conclusions: The healthcare expenditures associated with migraine with comorbid depression and/or anxiety are significantly higher than those without mental health comorbidities. Therefore, regular depression and anxiety screening for patients with migraine may help reduce the healthcare expenditures associated with depression and/or anxiety comorbidities and improve the quality of care.

Keywords: migraine, anxiety, depression, cost, healthcare 


\section{INTRODUCTION}

Migraine headache is a highly prevalent chronic condition among adults in the United States (US); around 16\% of US adults suffer from migraine (1). The World Health Organization (WHO) ranked migraine headache as the third cause of disability measured in years lived with disability (2). Migraine is associated with poor health-related quality of life $(3,4)$, disability $(4,5)$, and missed working days (6). Migraine is also associated with medication overuse (7). Furthermore, it is associated with a great economic burden in terms of direct medical costs (810) and indirect costs due to absenteeism in the workplace (11). Individuals with migraine are more likely to have higher healthcare expenditures than those without migraine $(8,9)$. Individuals with migraine also have a higher healthcare services utilization rate, such as emergency room and physician office visits, compared to those without migraine $(6,8,12)$.

Depression and/or anxiety are common among patients with migraine $(13,14)$. The likelihood of having a major depressive disorder along with migraine is significantly higher than their counterparts without migraine (15-17). Furthermore, it has been estimated that adults with migraine are two to four times more likely to suffer from depression and anxiety in comparison to the general population $(3,18-20)$. The comorbidity of depressive and anxiety disorders among migraine patients is associated with a high prevalence rate of disability (21), poor health-related quality of life $(3,4,21)$, and a high rate of healthcare utilization and costs (22).

The economic burden of migraine is high, with an estimated annual cost of $\$ 17$ billion in the US alone (23). However, this economic burden is significantly higher among patients with comorbid depression and/or anxiety $(22,24)$. Several studies have indicated that the healthcare expenditures associated with migraine with comorbid depression and/or anxiety can be double that of patients with migraine alone $(22,25)$. In a cohort study among adults with migraine using the 1-year data of a large employer-based insurance database, the presence of depression and/or anxiety along with migraine has resulted in higher direct medical costs than those with migraine alone $(\$ 5,589.5$ migraine alone $v s . \$ 10,223.4$ with anxiety and $\$ 10,582.2$ with depression) (22). Moreover, in a cross-sectional study that included 2,400 subjects with migraine between 2006 and 2012, the mean annual total healthcare expenditures as well as migraine-related healthcare expenditures were significantly higher among migraine patients with depression compared to those without a comorbid depression $(\$ 10,012$ vs. $\$ 4,740, P<$ 0.001 , and $\$ 723$ vs. $\$ 499, P=0.014$ ), respectively (25).

However, studies that compared the differences in healthcare expenditures among adults with migraine with or without comorbid anxiety and/or depression using nationally representative data are scarce. Thus, this study aimed to

Abbreviations: WHO, World Health Organization; YLDs, years lived with disability; HRQoL, health-related quality of life; MEPS, Medical Expenditure Panel Survey; AHRQ, Agency for Healthcare Research and Quality; ICD-9-CM, The International Classification of Diseases, Ninth Revision, Clinical Modification; ANOVA, analysis of variance; GLM, generalized linear model; SAS, statistical analysis system; STATA, Software for Statistics and Data Science. examine the differences in healthcare expenditures among adults with migraine alone and those with comorbid anxiety and/or depression, considering a myriad of factors that are likely to influence healthcare expenditures among this segment of the patient population. We hypothesized that adults with migraine alone have a lower healthcare expenditure as compared to those with comorbid anxiety and/or depression.

\section{METHODS}

\section{Study Design}

This study employed a cross-sectional study design using the Medical Expenditure Panel Survey (MEPS) data of 2012, 2014, and 2016.

\section{Data Source}

MEPS is a nationally representative complex panel survey design conducted by the Agency for Healthcare Research and Quality of the US non-institutionalized civilian population. It provides information on demographics, socioeconomic characteristics, medical conditions, health status, use of medical services, payments and charges, access to care, health insurance coverage, and other health-related data. The International Classification of Diseases, Ninth Revision, Clinical Modification (ICD-9-CM) codes was used to report the medical conditions. In 2016, the International Classification of Diseases, Tenth Revision, Clinical Modification (ICD-10-CM) codes were used to report medical conditions.

\section{Study Population}

Adults, aged 22-64 years, with migraine headache (based upon ICD-9 code of " 346 ," ICD-10 code of "G43") who were alive during the calendar years of 2012, 2014, and 2016 were included in this study. The study excluded adults without migraine headache and those aged $<22$ years. Three alternate years of data (2012, 2014, and 2016) were combined to increase the sample size. The use of alternate years is based on the recommendations of the Agency for Healthcare Research and Quality to avoid duplicate observations of the same participant (26).

\section{Measures}

\section{Dependent Variables}

\section{Type of and Total Healthcare Expenditures}

The types of healthcare expenditures, such as inpatient, outpatient, prescription, emergency room, and other healthcare expenditures (e.g., dental, vision, and durable medical equipment use, and others), were included in the analysis. Furthermore, the total healthcare expenditures, which consisted of the sum of all types of healthcare expenditures (including inpatient, outpatient, prescription drugs, emergency visits, and other expenditures), were estimated. All healthcare expenditures were adjusted using the consumer price index and were expressed in 2016 constant dollars provided by the US Bureau of Labor Statistics (27).

\section{Key Independent Variable}

The primary independent variable was the presentation of migraine, which included four mutually exclusive groups 
TABLE 1 | Characteristics of the study sample and number and row percentage of characteristics by migraine group among adults with migraine (Medical Expenditure Panel Survey data of 2012, 2014, and 2016).

\begin{tabular}{|c|c|c|c|c|c|c|c|c|c|c|c|}
\hline & \multicolumn{2}{|c|}{ Total sample } & \multicolumn{2}{|c|}{ Migraine alone } & \multicolumn{2}{|c|}{ Migraine and depression } & \multicolumn{2}{|c|}{ Migraine and anxiety } & \multicolumn{2}{|c|}{ Migraine and depression and anxiety } & \multirow[b]{2}{*}{$P$-value } \\
\hline & $N$ & Wt. \% & $N$ & Wt. \% & $N$ & Wt. $\%$ & $N$ & Wt.\% & $N$ & Wt.\% & \\
\hline All & 1,556 & 100 & 912 & 57.7 & 243 & 16.1 & 185 & 12.3 & 216 & 13.9 & \\
\hline \multicolumn{12}{|l|}{ Age in years } \\
\hline 22-39 & 661 & 40.3 & 419 & 62.0 & 79 & 13.1 & 90 & 13.6 & 73 & 11.4 & 0.049 \\
\hline $40-49$ & 421 & 26.9 & 240 & 57.7 & 70 & 16.9 & 43 & 9.9 & 68 & 15.5 & \\
\hline 50-64 & 474 & 32.8 & 253 & 52.5 & 94 & 19.1 & 52 & 12.6 & 75 & 15.7 & \\
\hline \multicolumn{12}{|l|}{ Gender } \\
\hline Women & 1,307 & 83.0 & 743 & 56.2 & 205 & 15.9 & 167 & 13 & 192 & 15 & 0.090 \\
\hline Men & 249 & 17.0 & 169 & 65.2 & 38 & 17.0 & 18 & 8.9 & 24 & 8.8 & \\
\hline \multicolumn{12}{|l|}{ Race/ethnicity } \\
\hline White & 850 & 74.3 & 458 & 55.3 & 141 & 16.8 & 116 & 12.7 & 135 & 15.2 & 0.020 \\
\hline African & 251 & 8.6 & 168 & 65.6 & 43 & 18.6 & 22 & 8.5 & 18 & 7.3 & \\
\hline \multicolumn{12}{|l|}{ American } \\
\hline Latino & 357 & 12.1 & 221 & 63 & 47 & 12.4 & 36 & 11.7 & 53 & 12.9 & \\
\hline Others & 98 & 5.0 & 65 & 68.2 & 12 & 9.1 & 11 & 13.2 & 10 & 9.4 & \\
\hline \multicolumn{12}{|l|}{ Marital status } \\
\hline Married & 782 & 56.8 & 505 & 62.4 & 105 & 14.7 & 80 & 10.0 & 92 & 12.9 & $<0.0001$ \\
\hline Widow & 229 & 13.1 & 106 & 40.3 & 49 & 21.2 & 30 & 15.7 & 44 & 22.8 & \\
\hline Sep/Div & 387 & 21.2 & 204 & 52.3 & 61 & 17.1 & 58 & 17.2 & 64 & 13.5 & \\
\hline Never married & 158 & 8.9 & 97 & 66.7 & 28 & 15.2 & 17 & 9.8 & 16 & 8.4 & \\
\hline \multicolumn{12}{|l|}{ Education level } \\
\hline LT HS & 142 & 5.8 & 77 & 50.2 & 37 & 28.1 & 11 & 7.7 & 17 & 14.0 & 0.076 \\
\hline HS & 198 & 11.8 & 110 & 58 & 34 & 16.4 & 23 & 11.5 & 31 & 14 & \\
\hline$>\mathrm{HS}$ & 922 & 64.3 & 531 & 56.7 & 127 & 14.8 & 117 & 13 & 147 & 15.6 & \\
\hline Missing & 294 & 18.1 & 194 & 63.7 & 45 & 16.7 & 34 & 11.7 & 21 & 7.9 & \\
\hline \multicolumn{12}{|l|}{ Region } \\
\hline Northeast & 268 & 17.6 & 156 & 58.9 & 34 & 11.6 & 38 & 14.3 & 40 & 15.1 & 0.670 \\
\hline Mid-west & 367 & 25.0 & 199 & 53.9 & 70 & 18.8 & 41 & 12 & 57 & 15.3 & \\
\hline South & 504 & 32.9 & 307 & 59.8 & 76 & 17.1 & 55 & 10.5 & 66 & 12.6 & \\
\hline West & 417 & 24.5 & 250 & 58.0 & 63 & 15.1 & 51 & 13.3 & 53 & 13.5 & \\
\hline \multicolumn{12}{|l|}{ Employment } \\
\hline Employed & 1,061 & 73.9 & 708 & 64.2 & 134 & 14.3 & 125 & 11.6 & 94 & 9.9 & $<0.0001$ \\
\hline Not employed & 495 & 26.1 & 204 & 39.4 & 109 & 21 & 60 & 14.3 & 122 & 25.3 & \\
\hline \multicolumn{12}{|l|}{ Poverty status ${ }^{a}$} \\
\hline Poor & 327 & 14.2 & 141 & 38.6 & 69 & 20.9 & 43 & 15.9 & 74 & 24.6 & $<0.0001$ \\
\hline Near poor & 317 & 15.1 & 184 & 53.1 & 48 & 15.8 & 38 & 14.6 & 47 & 16.5 & \\
\hline
\end{tabular}


TABLE 1 | Continued

\begin{tabular}{|c|c|c|c|c|c|c|c|c|c|c|c|}
\hline & \multicolumn{2}{|c|}{ Total sample } & \multicolumn{2}{|c|}{ Migraine alone } & \multicolumn{2}{|c|}{ Migraine and depression } & \multicolumn{2}{|c|}{ Migraine and anxiety } & \multicolumn{2}{|c|}{ Migraine and depression and anxiety } & \multirow[b]{2}{*}{$P$-value } \\
\hline & $N$ & Wt. \% & $N$ & Wt. \% & $N$ & Wt.\% & $N$ & Wt.\% & $N$ & Wt.\% & \\
\hline Middle income & 440 & 27.8 & 273 & 57.2 & 59 & 16.8 & 53 & 12.1 & 55 & 13.9 & \\
\hline High income & 472 & 42.9 & 314 & 66.1 & 67 & 14.1 & 51 & 10.3 & 40 & 9.5 & \\
\hline \multicolumn{12}{|l|}{ Health insurance } \\
\hline Private & 1,002 & 75.0 & 643 & 62.6 & 138 & 15.0 & 121 & 11.8 & 100 & 10.6 & $<0.0001$ \\
\hline Public & 416 & 18.1 & 182 & 38.9 & 85 & 20.2 & 55 & 16.2 & 94 & 24.8 & \\
\hline Uninsured & 138 & 6.8 & 87 & 54.5 & 20 & 17.2 & 9 & 6.8 & 22 & 21.5 & \\
\hline \multicolumn{12}{|l|}{ Rx insurance } \\
\hline Rx insurance & 884 & 68.1 & 569 & 62.8 & 115 & 14.5 & 114 & 12.2 & 86 & 10.6 & $<0.0001$ \\
\hline $\begin{array}{c}\text { No Rx } \\
\text { insurance }\end{array}$ & 672 & 31.9 & 343 & 47.0 & 128 & 19.5 & 71 & 12.3 & 130 & 21.1 & \\
\hline \multicolumn{12}{|l|}{ General health } \\
\hline $\begin{array}{l}\text { Excellent/very } \\
\text { good }\end{array}$ & 604 & 43.0 & 454 & 75.2 & 60 & 10.7 & 54 & 8.2 & 36 & 6.0 & $<0.0001$ \\
\hline Good & 519 & 32.2 & 298 & 53.4 & 89 & 17.9 & 66 & 14.6 & 66 & 14.1 & \\
\hline Fair/poor & 433 & 24.8 & 160 & 33.2 & 94 & 23 & 65 & 16.3 & 114 & 27.5 & \\
\hline \multicolumn{12}{|l|}{ Physical activity } \\
\hline 3/week & 657 & 42.9 & 439 & 65.1 & 78 & 12.6 & 77 & 13.2 & 63 & 9.1 & $<0.0001$ \\
\hline No exercise & 895 & 56.8 & 471 & 52.3 & 165 & 18.8 & 107 & 11.6 & 152 & 17.4 & \\
\hline \multicolumn{12}{|l|}{ Smoking } \\
\hline $\begin{array}{l}\text { Current } \\
\text { smoker }\end{array}$ & 271 & 16.3 & 121 & 41.7 & 54 & 20.4 & 37 & 13 & 59 & 24.9 & $<0.0001$ \\
\hline Others & 1,189 & 76.9 & 731 & 60.8 & 173 & 15.2 & 140 & 12.4 & 145 & 11.5 & \\
\hline Missing & 96 & 6.8 & 60 & 61.4 & 16 & 15.2 & 8 & 8.8 & 12 & 14.6 & \\
\hline \multicolumn{12}{|l|}{ Heart } \\
\hline Yes & 154 & 8.9 & 62 & 35.9 & 31 & 21.8 & 16 & 12.6 & 45 & 29.7 & $<0.0001$ \\
\hline No & 1,402 & 91.1 & 850 & 59.9 & 212 & 15.5 & 169 & 12.2 & 171 & 12.4 & \\
\hline \multicolumn{12}{|l|}{ Hypertension } \\
\hline Yes & 393 & 24.0 & 178 & 45.7 & 82 & 19.7 & 54 & 15.2 & 79 & 19.5 & 0.001 \\
\hline No & 1,163 & 76.0 & 734 & 61.5 & 161 & 14.9 & 131 & 11.3 & 137 & 12.2 & \\
\hline \multicolumn{12}{|l|}{ Diabetes } \\
\hline Yes & 128 & 7.2 & 54 & 39.9 & 21 & 13.9 & 19 & 17.7 & 34 & 28.5 & $<0.0001$ \\
\hline No & 1,428 & 92.8 & 858 & 59.1 & 222 & 16.2 & 166 & 11.8 & 182 & 12.8 & \\
\hline \multicolumn{12}{|l|}{ Hyperlipidemia } \\
\hline Yes & 781 & 48.3 & 433 & 55.7 & 137 & 17.2 & 88 & 10.7 & 123 & 16.5 & 0.091 \\
\hline No & 775 & 51.7 & 479 & 59.6 & 106 & 15 & 97 & 13.8 & 93 & 11.6 & \\
\hline \multicolumn{12}{|l|}{ Asthma } \\
\hline Yes & 240 & 14.8 & 108 & 45.0 & 48 & 19.6 & 30 & 14.9 & 54 & 20.5 & 0.006 \\
\hline No & 1,316 & 85.2 & 804 & 60.0 & 195 & 15.5 & 155 & 11.8 & 162 & 12.8 & \\
\hline
\end{tabular}




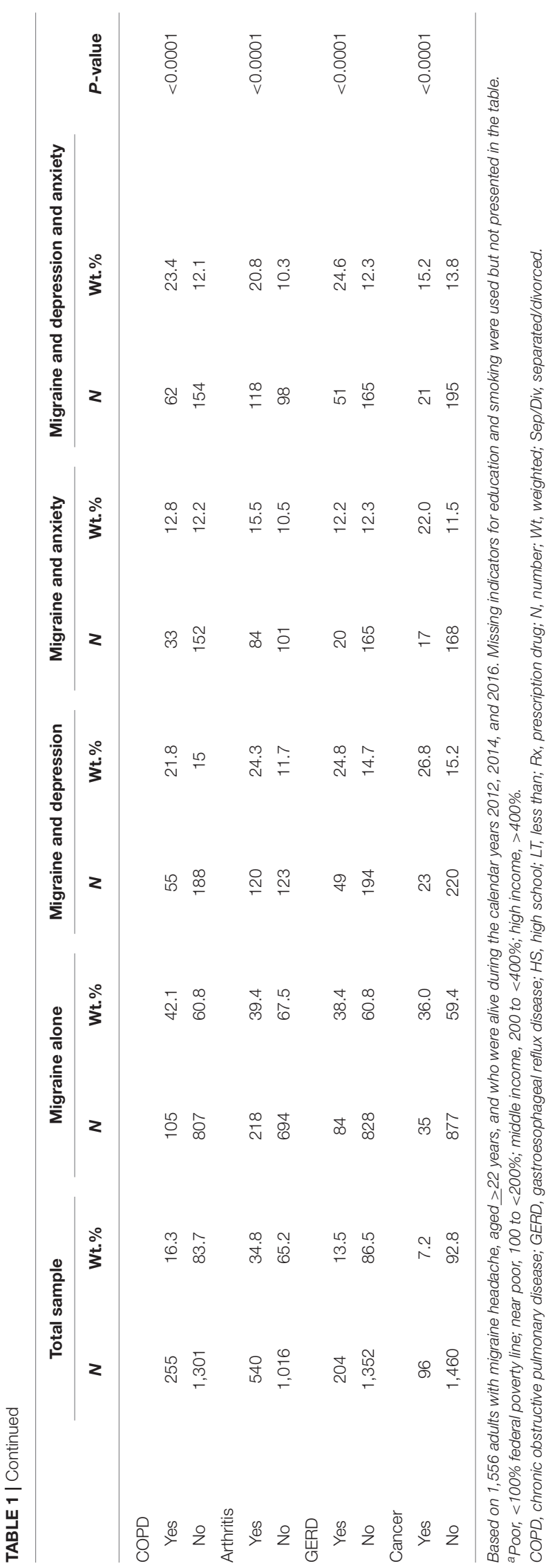

(migraine alone, migraine and anxiety, migraine and depression, and migraine with both conditions). Anxiety and depression were identified using the following clinical diagnostic codes (anxiety: CCS code of "651," ICD-10 code of "F40, F41;" depression: ICD-9 code of “296, 311," ICD-10 code of "F34, F39, and F32").

\section{Other Independent Variables}

The other independent variables that were considered were the sociodemographic characteristics, which included gender, age in years $(22-39,40-49$, and 50-64), race/ethnicity (White, African American, Latino, and other), marital status (married, widowed, separated/divorced, and never married), education (less than high school, high school, and above high school), region of residence (Northeast, Midwest, South, and West), employment (unemployed, employed), health insurance (public, private, and uninsured), prescription medication insurance (insured, uninsured), and poverty status (poor: $<100 \%$ federal poverty line; near poor: $100-<200 \%$; middle income: $200-$ $<400 \%$; and high income: $\geq 400 \%$ ). Other independent variables included personal health practices such as physical activity (three times/week, no exercise), smoking (smoker, non-smoker), perceived physical health (excellent/very good, good, and fair/ poor), and comorbid chronic health conditions such as diabetes, hypertension, and hyperlipidemia.

\section{Statistical Analysis}

Descriptive statistics were used to describe the study sample across the four migraine groups. One-way analysis of variance (ANOVA) was used to compare the unadjusted means of the total healthcare expenditures across the four migraine groups. Generalized linear model (GLM) regressions with log link were used to estimate the healthcare expenditures associated with comorbid anxiety and depression among individuals with migraine after adjusting for the confounders (sociodemographic characteristics, health insurance status, personal health practices, perceived physical health, and comorbid chronic health conditions). The GLM is an attractive alternative to ordinary least squares regressions on log-transformed expenditures because it corrects for heteroscedasticity and avoids retransformation bias (28). We used GLM with log link and gamma family distribution to estimate the adjusted medical expenditures associated with comorbid anxiety and depression. We also used a two-part model to estimate inpatient expenditures as the majority of the adults in the sample had zero inpatient expenditures. The first part of the model estimates the probability of having zero expenditure $v s$. positive expenditures. The second part of the model uses GLM to estimate the expenditures conditional on having positive inpatient expenditures. A $p$-value $<0.05$ was considered statistically significant. The primary sampling unit, strata, and weights provided in the MEPS were all used in the analysis. All analyses were performed using survey procedures in the Statistical Analysis System, SAS 9.4 (SAS Institute Inc., Cary, NC, USA) and the Software for Statistics and Data Science (STATA 15.1). 


\section{RESULTS}

\section{Description of the Study Sample}

The characteristics of the study sample who met the inclusion criteria $(n=1,556)$ are shown in Table 1 . The vast majority of patients were women $(83.0 \%)$, were white $(74.3 \%)$, and belong to the 22-39 years age group (40.3\%). Approximately $16 \%$ of the study sample had depression, $12.3 \%$ had an anxiety disorder, and $13.9 \%$ had both conditions. Sociodemographic and economic factors, personal health practices, and coexisting chronic conditions were significantly different across the four migraine groups $(P<0.05)$. For example, the percentage of patients who reported employment among patients with migraine alone (64.2\%) is significantly higher than their counterparts from other migraine groups, which were 14.3, 11.6, and $9.9 \%$ among patients with comorbid depression, comorbid anxiety, and comorbid depression and anxiety, respectively.

\section{Healthcare Expenditures by Migraine Groups}

The differences in healthcare expenditures associated with migraine between adults with migraine alone and those with comorbid anxiety and/or depression are shown in Table 2. The mean total healthcare expenditures among patients with migraine alone were significantly lower than their counterparts with comorbid anxiety and/or depression. Similarly, the mean inpatient, outpatient, prescription, and emergency healthcare expenditures were significantly lower among patients with migraine alone compared to other migraine groups. For example, total healthcare expenditures for individuals with migraine alone were $\$ 6,461$, which were significantly lower than the total healthcare expenditures for individuals with migraine and either comorbid anxiety $(\$ 11,102)$ or depression $(\$ 10,817)$ or with both comorbid anxiety and depression $(\$ 14,577)$.

\section{Adjusted Healthcare Expenditures by Migraine Groups}

The adjusted differences in healthcare expenditures between patients with migraine alone and those with comorbid anxiety and/or depression are shown in Table 3. Migraine with comorbid anxiety and depression was significantly associated with incremental costs of $\$ 1,027$ in outpatient and $\$ 662$ emergency room healthcare expenditures, compared to the migraine alone group after controlling for a multitude of covariates. Besides this, migraine with comorbid anxiety and/or depression was significantly associated with incremental costs of the prescription drug, compared to the migraine alone group after controlling for a multitude of covariates. However, migraine with comorbid depression and/or anxiety was not associated with significant incremental inpatient or other healthcare costs. Moreover, the incremental total healthcare costs were not significant for migraine patients with comorbid depression and/or anxiety.

\section{DISCUSSION}

The present study compared healthcare expenditures among subjects with migraine when diagnosed alone or with comorbid anxiety and/or depression. The study findings indicate that around half of adults with migraine had anxiety and/or depression; this is consistent with the findings of previously published studies (21). The high prevalence of depression and anxiety among adults with migraine and the significantly higher healthcare-related costs associated with it compared to the general population emphasize the need for incorporating depression and anxiety disorders screening into the routine clinical practice of managing migraine among adults. Adults with migraine who were diagnosed with comorbid anxiety and/or depression incurred two to three times higher total healthcare expenditures compared to those with migraine alone. This is consistent with the study of Pesa et al. who found that the presence of depression and/or anxiety along with migraine resulted in significantly higher total direct medical costs $(\$ 5,589$ migraine alone vs. $\$ 10,223$ with anxiety and $\$ 10,582$ with depression) (22). Furthermore, Wu et al. reported a higher mean annual total health expense for those with depression $(\$ 4,740$ migraine alone vs. $\$ 10,012$ with depression, $P<0.001)(25)$.

What distinguishes the current investigation from the previously published studies is the fact that the healthcare expenditures for anxiety and anxiety with depression comorbidity were identified after adjusting for a myriad of

TABLE 2 | Mean healthcare expenditures by migraine groups among adults with migraine (Medical Expenditure Panel Survey data of 2012, 2014, and 2016).

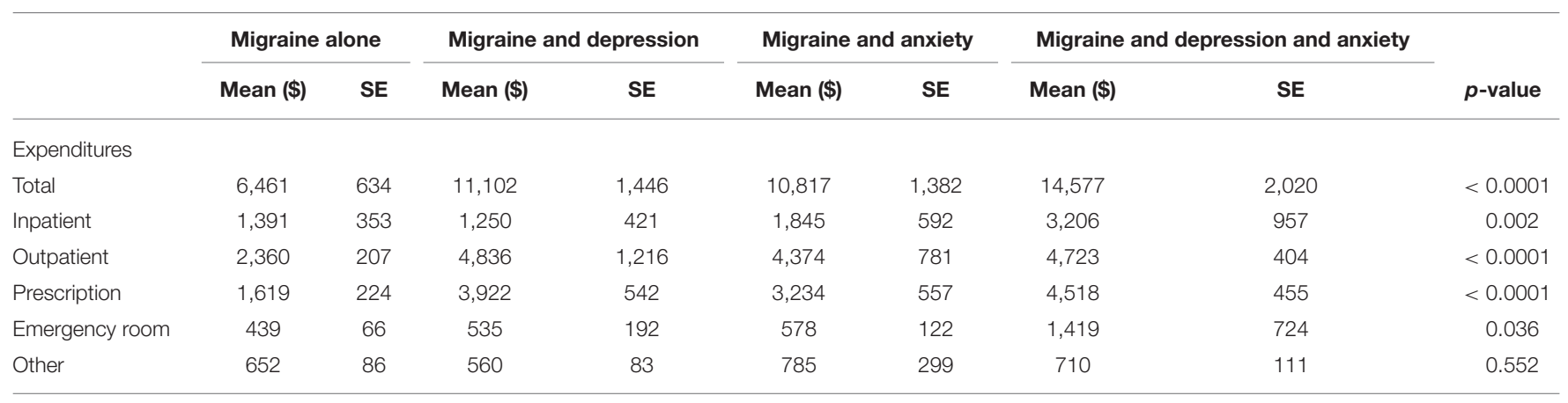

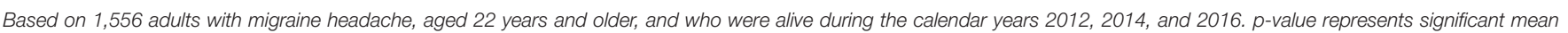
differences by migraine groups using ANOVA. Other expenditures included dental, vision, durable medical equipment use, and others.

\$, US dollar; SE, standard error. 
TABLE 3 | Intercept and parameter estimates for the migraine groups from generalized linear models with log link and gamma distribution on healthcare expenditures among adults with migraine (Medical Expenditure Panel Survey 2012, 2014, and 2016).

\begin{tabular}{|c|c|c|c|c|c|c|c|c|c|c|c|c|c|}
\hline & \multirow[b]{2}{*}{ Intercept (SE) } & \multicolumn{3}{|c|}{ Migraine and depression } & \multirow[b]{2}{*}{$p$-value } & \multicolumn{3}{|c|}{ Migraine and anxiety } & \multirow[b]{2}{*}{$p$-value } & \multicolumn{3}{|c|}{ Migraine and depression and anxiety } & \multirow[b]{2}{*}{$p$-value } \\
\hline & & $\beta$ & SE & Incremental cost & & $\beta$ & SE & Incremental cost & & $\beta$ & SE & Incremental cost & \\
\hline \multicolumn{14}{|c|}{ Unadjusted generalized linear model with log link and gamma distribution } \\
\hline Total & $8.77(0.09)$ & 0.54 & 0.15 & $\$ 4,641$ & 0.002 & 0.51 & 0.16 & $\$ 4,356$ & 0.005 & 0.81 & 0.17 & $\$ 8,116$ & $<0.0001$ \\
\hline Inpatient & $9.78(0.78)$ & -0.28 & 0.42 & $-\$ 141$ & 0.799 & 0.04 & 0.33 & $\$ 454$ & 0.525 & -0.07 & 0.30 & $\$ 1,815$ & 0.086 \\
\hline Outpatient & $7.76(0.08)$ & 0.71 & 0.21 & $\$ 2,476$ & 0.026 & 0.62 & 0.20 & $\$ 2,014$ & 0.014 & 0.69 & 0.12 & $\$ 2,363$ & $<0.0001$ \\
\hline Prescription & $7.38(0.14)$ & 0.88 & 0.19 & $\$ 2,302$ & $<0.0001$ & 0.69 & 0.23 & $\$ 1,616$ & 0.009 & 1.02 & 0.17 & $\$ 2,899$ & $<0.0001$ \\
\hline Emergency & $6.08(0.15)$ & 0.27 & 0.27 & $\$ 95$ & 0.639 & 0.27 & 0.27 & $\$ 140$ & 0.331 & 1.17 & 0.52 & $\$ 979$ & 0.177 \\
\hline Other & $6.47(0.13)$ & -0.15 & 0.19 & $-\$ 91$ & 0.432 & 0.18 & 0.40 & $\$ 133$ & 0.668 & 0.08 & 0.22 & $\$ 58$ & 0.710 \\
\hline \multicolumn{14}{|c|}{ Adjusted generalized linear model with log link and gamma distribution } \\
\hline Total & $10.61(0.41)$ & 0.11 & 0.11 & 1,025 & 0.330 & 0.09 & 0.12 & $\$ 871$ & 0.444 & 0.14 & 0.14 & $\$ 1,295$ & 0.312 \\
\hline Inpatient & $10.8(0.68)$ & -0.48 & 0.27 & $-\$ 1,332$ & 0.029 & -0.1 & 0.34 & $-\$ 707$ & 0.326 & -0.23 & 0.29 & $-\$ 589$ & 0.453 \\
\hline Outpatient & $8.46(0.43)$ & 0.15 & 0.12 & $\$ 515$ & 0.224 & 0.23 & 0.14 & $\$ 816$ & 0.129 & 0.29 & 0.13 & $\$ 1,027$ & 0.041 \\
\hline Prescription & $8.75(0.46)$ & 0.43 & 0.14 & $\$ 1,296$ & 0.005 & 0.52 & 0.16 & $\$ 1,598$ & 0.006 & 0.39 & 0.16 & $\$ 1,128$ & 0.017 \\
\hline Emergency & 7.89 (0.92) & 0.37 & 0.29 & $\$ 213$ & 0.281 & 0.68 & 0.36 & $\$ 460$ & 0.139 & 0.88 & 0.31 & $\$ 662$ & 0.032 \\
\hline Other & $6.11(0.58)$ & -0.16 & 0.16 & $-\$ 109$ & 0.307 & -0.32 & 0.18 & $-\$ 197$ & 0.075 & -0.04 & 0.21 & $-\$ 28$ & 0.849 \\
\hline
\end{tabular}

Based on 1,556 adults with migraine headache, aged 22 years and older, and who were alive during the calendar years 2012, 2014, and 2016. p-values denote statistical significance in parameter estimates from generalized linear models on expenditures with log link and gamma distribution. Other expenditures included dental, vision, durable medical equipment use, and others.

Reference group for migraine groups = migraine alone.

\$, US dollar; B, coefficient; $p$-value, probability value; $S E$, standard error. 
variables (22, 25). Significant differences between migraine groups with respect to outpatient healthcare expenditures and prescription drugs only were found. Migraine with comorbid anxiety and depression was significantly associated with incremental costs of $\$ 1,027$ in outpatient and $\$ 662$ emergency room healthcare expenditures and $\$ 1,128$ in prescription drug compared to the migraine alone group. The positive association between comorbid anxiety and depression and healthcare expenditures among adults with migraine has many potential explanations. For example, depression and/or anxiety may exacerbate migraine symptoms and increase the healthcare utilization rate, resulting in higher overall healthcare expenditures. Multiple observational studies with nationally representative samples among adult patients with migraine have reported that the comorbidity of migraine and depression was associated with higher rates of emergency department visits and all-cause office visits compared to those without depression $(20,25)$. Besides this, it is well-established that the comorbidity of migraine with depression and/or anxiety is associated with a higher rate of prescription drug utilization as reported by SMILE that was conducted among migraine patients visiting primary care clinics in France (29). Effective management of depressive and anxiety disorder among patients with migraine may reduce the rate of healthcare utilization and expenditures and improve the patients' quality of life. Therefore, future studies should examine the economic impact of proper depression and/or anxiety management among patients with migraine and whether this will lower the overall healthcare expenditures.

However, it has to be noted that migraine with comorbid depression and/or anxiety was associated with an increase in the total healthcare expenditures and inpatient and other expenditures, resulting in higher total healthcare expenditures compared to the migraine alone group. This association did not reach a statistically significant level in the adjusted analysis, where no significant difference in total healthcare expenditures, inpatient expenditures, and other expenditures was observed between the migraine groups. The lack of significant differences in the total healthcare expenditure between groups could be attributed to the fact that these psychiatric conditions can be associated with migraine at the sub-clinical level (i.e., subthreshold level), which means that the "migraine alone" group could be an inadequate control group $(30,31)$. One unexpected finding was the lower inpatient costs among patients with depression comorbidity, although depression comorbidity is associated with a higher rate of hospitalization and emergency room visits compared to migraine patients without depression $(20,25)$. These unexpected findings warrant further examination in future studies.

Several practical implications can emanate from the current study. The higher outpatient expenditures among migraine patients with comorbid depression and/or anxiety highlight the need to improve the quality of care provided to this segment of the patient population to improve their adherence to prescribed drug regimens which will eventually lower the rate of emergency room visits and hospitalization, resulting in lower overall healthcare costs. Besides this, regular depression and anxiety screening for patients with migraine may also reduce the healthcare expenditures associated with migraine and improve the quality of care through the early detection and management of these conditions.

Although this study has multiple merits, such as the use of nationally representative data, the control for multiple medical and socioeconomic factors, and the robustness of the findings using different statistical models, it should be interpreted in the context of some limitations. These limitations, such as the lack of control for the severity and the duration of the illness, should be acknowledged. This study did not also adjust the cost based on the frequency of migraine attacks in the four groups compared due to the lack of this data. Besides this, the over-thecounter expenditures are not captured in the MEPS database. This study has not also compared the healthcare expenditure with time. There is also lack of data about the subtype of migraine (episodic, chronic, with aura), preventive treatment, and medication overuse. Besides this, only direct costs from all causes are reported, as the MEPS data does not provide specific costs of the subgroup of migraine.

\section{CONCLUSIONS}

The current study has provided an updated estimate of the healthcare expenditures associated with migraine management with or without comorbid depression and/or anxiety among the adult US population. Its findings suggest that healthcare providers should be aware of the high prevalence of anxiety and depression among migraine patients that necessitates early detection and management of these comorbid conditions alongside migraine given the higher outpatient healthcare expenditures associated with these comorbid conditions.

\section{DATA AVAILABILITY STATEMENT}

The datasets generated for this study can be found in online repositories. The names of the repository/repositories and accession number(s) can be found below: The dataset supporting the conclusions of this article is available from the Medical Expenditure Panel Survey (MEPS) database and openly made available for researchers at the following website: https://meps. ahrq.gov/data_stats/download_data_files.jsp.

\section{AUTHOR CONTRIBUTIONS}

MA, YA, and AM have all contributed to the study conception and design. Data analysis was performed by MA and AM. The first draft of the manuscript was written by MA, YA, and AM. The authors have all commented on previous versions of the manuscript and read and approved the final manuscript.

\section{FUNDING}

The authors extend their appreciation to the Deanship of Scientific Research at King Saud University for funding this work through research group no. RG-1441-366. 


\section{REFERENCES}

1. Burch R, Rizzoli P, Loder E. The prevalence and impact of migraine and severe headache in the United States: figures and trends from government health studies. Headache. (2018) 58:496-505. doi: 10.1111/head.13281

2. Steiner TJ, Stovner LJ, Vos T. GBD 2015: migraine is the third cause of disability in under 50s. J Headache Pain. (2016) 17:104. doi: 10.1186/s10194-016-0699-5

3. Lipton RB, Hamelsky SW, Kolodner KB, Steiner TJ, Stewart WF. Migraine, quality of life, and depression. A population-based case-control study. Neurology. (2000) 55:629-35. doi: 10.1212/WNL.55.5.629

4. Lipton RB, Liberman J, Kolodner K, Bigal M, Dowson A, Stewart W. Migraine headache disability and health-related quality-of-life: a populationbased case-control study from England. Cephalalgia. (2003) 23:44150. doi: 10.1046/j.1468-2982.2003.00546.x

5. Lipton RB, Bigal ME, Diamond M, Freitag F, Reed ML, Stewart WF. Migraine prevalence, disease burden, and the need for preventive therapy. Neurology. (2007) 68:343-9. doi: 10.1212/01.wnl.0000252808.97649.21

6. Sumelahti ML, Sumanen M, Sumanen MS, Tuominen S, Vikkula J, Honkala SM, et al. My Migraine Voice survey: disease impact on healthcare resource utilization, personal and working life in Finland. J Headache Pain. (2020) 21:020-01185. doi: 10.1186/s10194-020-01185-4

7. López Martínez MdV, Pareja Román J, Jiménez Hernández MD, Maestu Unturbe C, Ramírez-Castillejo MdC. Chronic migraine with medication overuse: clinical pattern and evolution from a retrospective cohort in Seville, Spain. SN Comprehens Clin Med. (2020) 2:1514-25. doi: 10.1007/s42399-020-00424-8

8. Elston Lafata J, Moon C, Leotta C, Kolodner K, Poisson L, Lipton RB. The medical care utilization and costs associated with migraine headache. J Gen Intern Med. (2004) 19:1005-12. doi: 10.1111/j.1525-1497.2004.30021.x

9. Hawkins K, Wang S, Rupnow M. Direct cost burden among insured US employees with migraine. Headache. (2008) 48:55363. doi: $10.1111 /$ j.1526-4610.2007.00990.x

10. Hazard E, Munakata J, Bigal ME, Rupnow MF, Lipton RB. The burden of migraine in the United States: current and emerging perspectives on disease management and economic analysis. Value Health. (2009) 12:5564. doi: 10.1111/j.1524-4733.2008.00404.x

11. Hawkins K, Wang S, Rupnow MF. Indirect cost burden of migraine in the United States. J Occup Environ Med. (2007) 49:368-74. doi: 10.1097/JOM.0b013e31803b9510

12. Stokes M, Becker WJ, Lipton RB, Sullivan SD, Wilcox TK, Wells L, et al. Cost of health care among patients with chronic and episodic migraine in Canada and the USA: results from the International Burden of Migraine Study (IBMS). Headache. (2011) 51:1058-77. doi: 10.1111/j.1526-4610.2011.0 1945.x

13. Bigal ME, Lipton RB. The epidemiology, burden, and comorbidities of migraine. Neurol Clin. (2009) 27:321-34. doi: 10.1016/j.ncl.2008. 11.011

14. Yu S, Zhang Y, Yao Y, Cao H. Migraine treatment and healthcare costs: retrospective analysis of the China Health Insurance Research Association (CHIRA) database. J Headache Pain. (2020) 21:020-01117. doi: 10.1186/s10194-020-01117-2

15. Jette N, Patten S, Williams J, Becker W, Wiebe S. Comorbidity of migraine and psychiatric disorders-a national population-based study. Headache. (2008) 48:501-16. doi: 10.1111/j.1526-4610.2007.00993.x

16. Korolainen MA, Tuominen S, Kurki S, Lassenius MI, Toppila I, Purmonen $\mathrm{T}$, et al. Burden of migraine in Finland: multimorbidity and phenotypic disease networks in occupational healthcare. J Headache Pain. (2020) 21:8. doi: 10.1186/s10194-020-1077-x
17. Buse DC, Reed ML, Fanning KM, Bostic R, Dodick DW, Schwedt TJ, et al. Comorbid and co-occurring conditions in migraine and associated risk of increasing headache pain intensity and headache frequency: results of the migraine in America symptoms and treatment (MAST) study. $J$ Headache Pain. (2020) 21:020-1084. doi: 10.1186/s10194-020-1084-y

18. Antonaci F, Nappi G, Galli F, Manzoni GC, Calabresi P, Costa A. Migraine and psychiatric comorbidity: a review of clinical findings. J Headache Pain. (2011) 12:115. doi: 10.1007/s10194-010-0282-4

19. Hamelsky SW, Lipton RB. Psychiatric comorbidity of migraine. Headache. (2006) 46:1327-33. doi: 10.1111/j.1526-4610.2006.00576.x

20. Kalaydjian A, Merikangas K. Physical and mental comorbidity of headache in a nationally representative sample of US adults. Psychosom Med. (2008) 70:773. doi: 10.1097/PSY.0b013e31817f9e80

21. Lantéri-Minet M, Radat F, Chautard M-H, Lucas C. Anxiety and depression associated with migraine: influence on migraine subjects' disability and quality of life, and acute migraine management. Pain. (2005) 118:31926. doi: 10.1016/j.pain.2005.09.010

22. Pesa J, Lage MJ. The medical costs of migraine and comorbid anxiety and depression. Headache. (2004) 44:56270. doi: 10.1111/j.1526-4610.2004.446004.x

23. Goldberg LD. The cost of migraine and its treatment. Am J Manag Care. (2005) 11:S62-7.

24. Bonafede M, Cai Q, Cappell K, Kim G, Sapra SJ, Shah N, et al. Factors associated with direct health care costs among patients with migraine. J Manag Care Spec Pharm. (2017) 23:1169-76. doi: 10.18553/jmcp.2017.23.11.1169

25. Wu J, Davis-Ajami ML, Kevin $\mathrm{Lu} \mathrm{Z}$. Impact of depression on health and medical care utilization and expenses in US adults with migraine: a retrospective cross sectional study. Headache. (2016) 56:1147-60. doi: 10.1111/head.12871

26. Sommers JP. An Examination of State Estimates Using Multiple Years of Data From the Medical Expenditure Panel Survey, Household Component. Rockville, MD: Agency for Healthcare Research and Quality (2006).

27. U.S. Bureau of Statistics. Consumer Price Index for All Urban Consumers: Medical Care Services. (2019). Available online at: https://fred.stlouisfed.org/ series/CUSR0000SAM2 (accessed December 15, 2020).

28. Jones AM, Rice N, d'Uva TB, Balia S. Applied Health Economics. London: Routledge (2013). doi: 10.4324/9780203102411

29. Radat F, Mekies C, Géraud G, Valade D, Vivès E, Lucas C, et al. Anxiety, stress and coping behaviours in primary care migraine patients: results of the SMILE study. Cephalalgia. (2008) 28:1115-25. doi: 10.1111/j.1468-2982.2008.01644.x

30. Lucchetti G, Peres MF, Lucchetti AL, Mercante JP, Guendler VZ, Zukerman E. Generalized anxiety disorder, subthreshold anxiety and anxiety symptoms in primary headache. Psychiatry Clin Neurosci. (2013) 67:419. doi: 10.1111/j.1440-1819.2012.02405.x

31. Peres MFP, Mercante JP, Tobo PR, Kamei H, Bigal ME. Anxiety and depression symptoms and migraine: a symptom-based approach research. $J$ Headache Pain. (2017) 18:37. doi: 10.1186/s10194-017-0742-1

Conflict of Interest: The authors declare that the research was conducted in the absence of any commercial or financial relationships that could be construed as a potential conflict of interest.

Copyright (๑) 2021 Alwhaibi, Meraya and AlRuthia. This is an open-access article distributed under the terms of the Creative Commons Attribution License (CC BY). The use, distribution or reproduction in other forums is permitted, provided the original author(s) and the copyright owner(s) are credited and that the original publication in this journal is cited, in accordance with accepted academic practice. No use, distribution or reproduction is permitted which does not comply with these terms. 